\title{
Protective effect of Solanum tuberosum against the breakdown of red blood cells: an experimental study in burn injury model
}

\author{
Emin Zümrütdal ${ }^{1 *}$, Tuna Bilecik², Basak Unver Koluman ${ }^{3}$, Umit Turan $^{2}$, Kenan Daglioglư ${ }^{4}$, Murat Gunduz $^{5}$, \\ Mustafa Gencoglu' ${ }^{6}$, Sadik Dincer ${ }^{6}$, Suleyman Cetinkunar ${ }^{2}$ \\ ${ }^{1}$ Department of Surgery, EPC Hospital, Adana, Turkey \\ ${ }^{2}$ Department of Surgery,Adana Numune Research and Training Hospital, Adana, Turkey \\ ${ }^{3}$ Department of Haematology, Adana Numune Research and Training Hospital, Adana, Turkey \\ ${ }^{4}$ Animal Research Center, University of Cukurova, Adana, Turkey \\ ${ }^{5}$ Department of anesthesia and reanimation University of Cukurova, Adana, Turkey \\ ${ }^{6}$ Department of biology, Science and letter faculty, University of Cukurova, Adana Turkey
}

\section{A R T I C L E I N F 0}

Article Type:

Original Article

\section{Article History:}

Received: 8 May 2017

Accepted: 19 October 2017

\section{Keywords:}

Burn injury

Mice

Solanum tuberosum

Anemia

\begin{abstract}
A B S T R A C T
Introduction: Anemia is known to be an important problem in burn injury. We aimed to investigate the protective effect of Solanum tuberosum (potatoes), against abnormal breakdown of erythrocytes in burn injury.

Methods: Ninety-six male (9 to 10 weeks old) Swiss Albino mice (34-40 g) were included into the study, which consisted of two phases: dose optimization phase $(n=48)$ and study phase $(n=48)$. Half of the mice were given S. tuberosum juice (study group) and the other half drinking water (control group). The optimal dosage causing minimum decline in hematocrit was as follows: $1.6 \mathrm{~mL} / \mathrm{kg}$ at $0 \mathrm{~h}$, $0.8 \mathrm{~mL} / \mathrm{kg}$ at 24 hours, and $0.8 \mathrm{~mL} / \mathrm{kg}$ at 36 hours of burn injury. The burn injury was induced with a solid $10-\mathrm{mm}$ aluminum bar heated in boiling water.

Results: The decrease in hematocrit level was significantly lower in the study group than the control group at 24 and 48 hours $(P=0.05$ and $P=0.023$, respectively). The increase in anisocytosis, a hemolytic anemia sign, was also significantly lower in the study group than the control group at 48 hours $(P=0.021)$. There was no significant difference between groups in terms of clotting time or the bleeding time.

Conclusion: In burn injury, S. tuberosum may be beneficial against anemia and it may reduce the need for red blood cell transfusion.
\end{abstract}

Implication for health policy/practice/research/medical education:

The Solanum tuberosum seriously prevented the formation of anemia due to the burn in the first 48 hours. Therefore the isolation of active compounds may lead to the development of new drugs in the prevention of anemia

Please cite this paper as: Zumrutdal E, Bilecik T, Koluman B, Turan U, Daglioglu K, Gunduz M, et al. Protective effect of Solanum tuberosum against the breakdown of red blood cells: an experimental study in burn injury model. J Herbmed Pharmacol. 2018;7(1):13-17. doi: 10.15171/jhp.2018.03

\section{Introduction}

In severe traumas like burn injury, anemia is a serious problem caused mainly by hemolytic mechanisms (1-4). Burn patients generally develop non-immune hemolytic anemia, which is characterized by abnormal breakdown of red blood cells $(5,6)$. Anemia that develops in severely burned patients within hours is generally progressive and negatively affects the morbidity and mortality of the patients. Several treatments may be needed for the correction of this anemia, including red cell transfusion.
Experimental studies on rats showed that burn injury induced high rate of erythrocyte destruction (7). Continuously discussed blood transfusion in burn patients. Blood is given to the patient in the physiological condition. Because of the risk of blood transfusion, this treatment is very well appreciated. Anemia can occur not only in burn patient, but also in conditions such as cancer and chronic rheumatic diseases. So it is very important to prevent it before anemia occurs. So the study we are doing is highly valued for the prevention of the anemia in the 
chronic diseases that are more common with the increase of the average age in humans.

Herbal treatments are used in many diseases (8). Different herbal treatments have been applied for anemia. Cultural treatments vary according to regions in the world. In some regions Solanum tuberosum has been used for the treatment of anemia (9). But, the efficacy of the treatment of anemia in the S. tuberosum has not been clearly explained. In this study, we aimed to evaluate the protective effect of $S$. tuberosum on abnormal breakdown of erythrocytes in burn injury.

\section{Materials and Methods}

Study design and animals

This experimental study was conducted on 96 male (9 to 10 weeks) Swiss albino mice (34-40 g). In order to ensure a natural environment before the experiment, the mice were kept in seclusion for 5 days at the same room temperature with 12 hours of light and 12 hours of darkness each day. During the whole observation and experiment process, all mice received the same food and water. The study procedures were approved by the Animal Ethics Committee of the Medical Experimental Research Center of Cukurova University (No. 27.4.2016/1).

\section{Burn injury}

The animals were anesthetized by administering intramuscular xylazine $10 \mathrm{mg} / \mathrm{kg}$ + ketamine $150 \mathrm{mg} / \mathrm{kg}$ through the gluteal region $(10,11)$. When the animals were properly anesthetized, trichotomy of back was performed using antisepsis with $10 \%$ polyvinylpyrrolidone iodine. Thermal injuries were created with a solid aluminum bar (10 $\mathrm{mm}$ in diameter), which was previously heated in boiling water to elevate the temperature of the bar to $100^{\circ} \mathrm{C}$. The bar was kept in contact with the animal skin on the dorsal proximal region for 11 seconds without applying extra pressure. The pressure exerted on the animal skin corresponded to the mass of $140 \mathrm{~g}$ of aluminum bar used in the burn induction. In order to further minimize the margin of error in methodology, 4 different aluminum bars, which possessed the same mechanism, were employed (12).

Preparation and administration of Solanum Tuberosum juice

Newly harvested S. tuberosum (potatoes) without budding or green coloration on the peelings was used for the study. Potatoes were washed under the drinking water. After pealed 2-3 $\mathrm{mm}$ in thickness, they were washed in the drinking water for the second time and dried with paper towels. Potatoes were grated, and their juice was filled in a sterile container by squeezing with hands at the ambient temperature. The obtained juice was left to rest for 3 minutes, and the liquid arising at the top of the container was transferred into another tube and administered to the animals through the oral gavages without delay. While the study group underwent such a procedure, the control animals were given the same dose of drinking water through the oral gavages in order to induce the same stress condition.

The study consisted of two phases. In the 1st phase, dose optimization was performed in 48 mice by applying three different dose schemes of $S$. tuberosum or drinking water, each to 16 mice with burn injury (Table 1 ).

The hematocrit (Ht) levels at the 0,24 , and 48 hours were compared between various dose schemes. Among three dose schemes, the optimal one that caused minimum decline in the amount of $\mathrm{Ht}$ within the scope of erythrocyte destruction was scheme $\mathrm{C} 1$ and $\mathrm{C} 2: 1.6 \mathrm{~mL} / \mathrm{kg}$ at 0 hour of burn injury, $0.8 \mathrm{~mL} / \mathrm{kg}$ at 24 hours, and $0.8 \mathrm{~mL} / \mathrm{kg}$ at 36 hours (Table 2).

At the second phase of the study, the optimal dose of $S$. tuberosum (study group) and drinking water (control group) determined in the first phase of the study was applied into the other 48 mice. Among these mice, $\mathrm{Ht}$ levels, peripheral smear, were evaluated in 16 mice at 0 , 24 , and 48 hours, bleeding time and clotting time were evaluated in 16 mice at 24 and 48 hours.

\section{Hematocrit test}

At 0,24 , and 48 hours, the mouse tail was cut to $0.5 \mathrm{~cm}$ and the blood samples taken into heparinized tubes were studied without delay. The Ht pipets were placed in the $\mathrm{Ht}$ centrifuge machine (Thermo-Pico Eraeus) and centrifuged at $10000 \mathrm{rpm}$ for 5 minutes and read according to the Ht scale. The results were expressed as percentages. The Ht value at 0 hour was considered $100 \%$ (basal level), and the Ht values at 24 and 48 hours were determined to compare the Ht basal level.

\section{Histopathological examination}

The peripheral smear was performed by a hematology not knowing the study and control groups. In the second phase of the study, prior to the blood sample collection for Ht examination, a drop of blood taken on the lam was prepared for the peripheral blood smear. It was stained with Giemsa stain and peripheral smear was evaluated under 100x enlarged view (Nikon, Japan, Model Alphaphot-2). The erythrocytes exhibiting hemolytic anemia signs in the peripheral smear test were evaluated for rate of anisocytosis, poikilocytosis, polychromasia, and schistocytes in cells, and the resulting values were

Table 1. Dose schemes of drinking water/S. tuberosum juice during dose optimization phase

\begin{tabular}{lcccc}
\hline Dose schemes & 0th $\mathbf{h}$ & 12th $\mathbf{~}$ & 24th $\mathbf{~}$ & 36th $\mathbf{~}$ \\
\hline A1 (water), $\mathrm{mL} / \mathrm{kg}$ & 8 & 8 & 8 & 8 \\
A2 (S. tuberosum), $\mathrm{LL} / \mathrm{kg}$ & 8 & 8 & 8 & 8 \\
B1 (water), $\mathrm{mL} / \mathrm{kg}$ & 1.6 & - & 1.6 & - \\
B2 (S. tuberosum), $\mathrm{mL} / \mathrm{kg}$ & 1.6 & - & 1.6 & - \\
C1 (water), mL/kg & 1.6 & - & 0.8 & 0.8 \\
C2 (S. tuberosum), $\mathrm{mL} / \mathrm{kg}$ & 1.6 & - & 0.8 & 0.8 \\
\hline
\end{tabular}


Table 2. The comparison of the $\mathrm{Ht}$ values and \% change in $\mathrm{Ht}$ at the 0th, 24th and 48th hours between control and study groups in various dosing scheme during optimization phase of the study

\begin{tabular}{|c|c|c|c|c|c|c|c|c|}
\hline \multirow{2}{*}{ Dose schemes } & & \multirow{2}{*}{$\mathbf{N}$} & \multicolumn{2}{|c|}{ Oth hour } & \multicolumn{2}{|c|}{ 24th hour } & \multicolumn{2}{|c|}{ 48th hour } \\
\hline & & & $\mathrm{Ht} \%$ & $\%$ Change & $\mathrm{Ht} \%$ & $\%$ Change & $\mathrm{Ht} \%$ & \% Change \\
\hline $\mathrm{A} 1$ & Control group & 8 & 46.5 & 100 & 42.13 & 91 & 41.38 & 89 \\
\hline A2 & Study group & 8 & 44.38 & 100 & 42.63 & 96 & 40.5 & 91.3 \\
\hline$P$ & & & 0.162 & & 0.725 & & 0.519 & \\
\hline B1 & Control group & 8 & 46 & 100 & 40.29 & 87.6 & 38.25 & 83 \\
\hline B2 & Study group & 8 & 46.5 & 100 & 44.6 & 96.0 & 41.75 & 89.8 \\
\hline$P$ & & & 0.708 & & 0.001 & & 0.007 & \\
\hline $\mathrm{C} 1$ & Control group & 8 & 45.13 & 100 & 41.5 & 92 & 39.63 & 87.8 \\
\hline $\mathrm{C} 2$ & Study group & 8 & 45.75 & 100 & 44.88 & 98.1 & 43.5 & 95.1 \\
\hline $\mathrm{P}$ & & & 0.494 & & 0.001 & & 0.001 & \\
\hline
\end{tabular}

compared between the groups. In the light of the examination and comparisons the anemia was classified as grade 1, grade 2, and grade 3 (13-15) (Table 3).

\section{Clotting time}

The clotting time was investigated with the lam method. Blood samples were taken from two different points of the tail on the lam without contacting the tissue. The stopwatch was started. After 1 minute, the pin of a needle was passed through the first blood droplet at every 30 seconds to check whether a blood clot adhered to the needle. At the moment when the clot adhered to the needle, the second blood droplet was checked at every 30 seconds till clotting was observed. The time of the clotting of the second blood droplet was considered as the actual clotting time and recorded in minute.

\section{Bleeding time}

The Duke method was applied with modifications. A stopwatch different from the one used in the clotting time control was used. The stopwatch was started. After the collection of blood samples from the tail for clotting time examination, the mouse was fixed by hand and the blood on the tail was contacted to distinctive parts of the filter paper to ensure that the paper absorbed the blood. When the bleeding stopped, the stopwatch was halted. The bleeding time was identified and recorded in minutes.

Statistical analysis

Statistical analyses were performed with the SPSS software
(SPSS, version 17.0, IBM Corporation, Armonk, NY, USA). The independent samples $t$ test was used to analyze the numeric data of the hematocrit of mice. The results of the peripheral blood smear were compared with the chi-square test between groups. The value of $P<0.05$ was considered to be statistically significant.

\section{Results}

Hematocrit levels

The decrease in the Ht level was significantly lower in the group receiving potatoes (study group) as compared to the control group at 24 and 48 hours $(P=0.05$ and $P=0.023$, respectively, Table 4).

\section{Peripheral smear}

The peripheral smear results were checked at 0,24 , and 48 hours in both groups. No difference was observed between the groups at the 0 hour. The hemolytic anemia signs of hypochromia, anisocytosis, poikilocytosis, polychromasia, and schistocytes were more common in the peripheral smear of the control group at 24 hours as compared to the group receiving potatoes (study group). However, the difference was not statistically significant $(P$ $>0.05)$. On the other hand, compared to study group, the increase in the anisocytosis at 48 hours was significantly higher $(P=0.021$; Figure 1$)$. Even though the amount of the other hemolytic anemia signs, namely hypochromia, poikilocytosis, polychromasia, and schistocytes, was higher in the control group, there was no statistically significant difference between the groups $(P>0.05)$.

Table 3. The scoring of abnormal blood cells according to the peripheral smear

\begin{tabular}{|c|c|c|c|}
\hline GRADE & 1 & 2 & 3 \\
\hline Hypochromia & $\begin{array}{l}\text { Area of central pallor is } 0 \%-25 \% \text { of the cell } \\
\text { diameter }\end{array}$ & $\begin{array}{l}\text { Area of central pallor is } 25 \%-50 \% \\
\text { of the cell diameter }\end{array}$ & $\begin{array}{l}\text { Area of pallor is more than } 50 \% \\
\text { of the cell diameter }\end{array}$ \\
\hline $\begin{array}{l}\text { Anisocytosis / } \\
\text { Poikilocytosis }\end{array}$ & $\begin{array}{l}10 \%-25 \% \text { of cells that differ in size or shape from } \\
\text { normal RBCs }\end{array}$ & $\begin{array}{l}25 \%-50 \% \text { of cells that differ in size } \\
\text { or shape from normal RBCs }\end{array}$ & $\begin{array}{l}>50 \% \text { of cells that differ in size or } \\
\text { shape from normal RBCs }\end{array}$ \\
\hline Polychromasia & $1 \%-2 \%$ of red cells that are polychromatophilic & $\begin{array}{l}3 \%-4 \% \text { of red cells that are } \\
\text { polychromatophilic }\end{array}$ & $\begin{array}{l}\geq 5 \% \text { of red cells that are } \\
\text { polychromatophilic }\end{array}$ \\
\hline $\begin{array}{l}\text { Schistocytes } \\
0-1 \% \text { percentage of } \\
\text { red cells }\end{array}$ & $1-5 \%$ of red cells & $>5 \%$ & \\
\hline
\end{tabular}


Table 4. The comparison of the Ht values and percent changes in the Hct values at the 0th, 24th and 48th hours

\begin{tabular}{|c|c|c|c|c|c|c|c|}
\hline & \multirow{2}{*}{$n$} & \multicolumn{2}{|c|}{ Oth hour } & \multicolumn{2}{|c|}{ 24th hour } & \multicolumn{2}{|c|}{ 48th hour } \\
\hline & & $\mathrm{Ht} \%$ & $\%$ Change & $\mathrm{Ht} \%$ & $\%$ Change & $\mathrm{Ht} \%$ & $\%$ Change \\
\hline Control group & 8 & $39.43 \pm 3.82$ & 100 & $34.25 \pm 4.68$ & 86.9 & $34.25 \pm 4.23$ & 86.9 \\
\hline Study group & 8 & $42.75 \pm 2.49$ & 100 & $40.63 \pm 2.55$ & 95 & $38.88 \pm 2.85$ & 90.9 \\
\hline$P$ & & \multicolumn{2}{|c|}{$>0.05$} & \multicolumn{2}{|c|}{0.05} & \multicolumn{2}{|c|}{0.023} \\
\hline
\end{tabular}
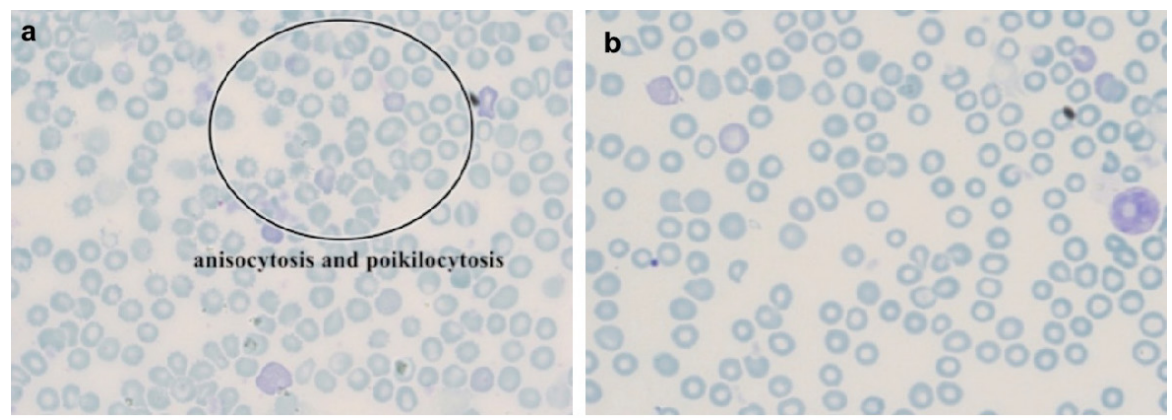

Figure 1. Anisocytosis in control group (a) and Solanum tuberosum group (b). This increase in the anisocytosis at $48 \mathrm{~h}$ was significantly higher in the control group compared with the Solanum tuberosum- administered study group.

\section{Clotting and bleeding times}

No statistically significant difference was observed between the groups regarding either the clotting time or the bleeding time at 0,24 , and 48 hours (Table 5).

\section{Discussion}

Various cultural treatments are applied in different regions of the world. One of these forms of treatment is the use of S. tuberosum for anemia.

In this study, we investigated the S. tuberosum plant for the protection of the anemia of the body under burn injury in mice. We observed that the $\mathrm{Ht}$ levels were protected at 24 and 48 hours closer to the normal values in the group receiving potato juice compared to control group $(P<$ 0.05 ). As seen in Tables 2 and 4, statistically significant results were found by a repetition of the same study. However, the difference in $P$ values $(0.023$ and 0.001$)$ is based on the fact of the conduction of the studies at different times. The reliability of this study is increased by the fact that statistically significant results were obtained again.

The protection of hemolysis in the injection of high doses of $S$. tuberosum during the optimization process

Table 5. The change clotting time, and bleeding time in control and study groups

\begin{tabular}{lccc}
\hline & 0th hour & 24th hour & 48th hour \\
\hline Clotting time $(\mathrm{min})$ & & & \\
Control group $(\mathrm{n}=8)$ & $4.56 \pm 0.41$ & $4.56 \pm 0.41$ & $4.44 \pm 0.1$ \\
Study group $(\mathrm{n}=8)$ & $4.44 \pm 0.49$ & $4.5 \pm 0.53$ & $4.5 \pm 0.37$ \\
$P$ & $>0.05$ & $>0.05$ & $>0.05$ \\
Bleeding time $(\mathrm{min})$ & & & \\
Control group $(\mathrm{n}=8)$ & $1.75 \pm 0.26$ & $1.75 \pm 0.26$ & $1.81 \pm 0.25$ \\
Study group $(\mathrm{n}=8)$ & $1.88 \pm 0.35$ & $1.69 \pm 0.25$ & $1.81 \pm 0.37$ \\
$P$ & $>0.05$ & $>0.05$ & $>0.05$ \\
\hline
\end{tabular}

is thought to be based on the hemolysis effect of the solanine inside the S. tuberosum (16). We also found that on peripheral smear there were fewer signs of hemolysis in the $S$. tuberosum group in comparison with the control group without statistical significance $(P>0.05)$, whereas the signs of anisocytosis were significantly fewer at 48 hours $(P<0.05)$.

Protected Ht levels and decreased hemolytic signs in the $S$. tuberosum group show that we achieved the aim of therapeutic targets. Moreover, as the bleeding time and clotting time were preserved in all groups, it may be conceivable that $S$. tuberosum affects erythrocyte functionality but does not have any influence on the factors related to coagulation.

The results of this study indicate that, in the cases of severe burn injury and trauma, S. tuberosum may be beneficial in the treatment of severe anemia occurring to eliminate the need for red blood cell transfusion in early stage.

According to our literature review, there is no other similar study on the subject of the present article. Our results may bring forward new modern treatment options targeting pathophysiologic factors instead of blood transfusion. However, there should be further, large scale clinical studies to come to solid conclusions.

Limitation: Because of the low amount of the sample taken from mice, free hemoglobin and haptoglobin levels were not evaluated together with other parameters in this study on burns.

As the oxidative stress markers are already high and such a study may be considered to be a separate study on itself, they were not assessed within the scope of the study.

\section{Conflict of interests}

The authors declare no conflict of interest. 


\section{Ethical considerations}

Ethical issues have been observed by the authors.

\section{Funding/Support}

None.

\section{References}

1. Bernat I, Novak J, Elek S, Dozsan G. Anaemia after thermal injury. I. Iron metabolism. Acta Med Acad Sci Hung. 1965;21:121-31.

2. Endoh Y, Kawakami M, Orringer EP, Peterson HD, Meyer AA. Causes and time course of acute hemolysis after burn injury in the rat. J Burn Care Rehabil. 1992;13(2 Pt 1):203-9.

3. Wallner SF, Vautrin R. The anemia of thermal injury: mechanism of inhibition of erythropoiesis. Proc Soc Exp Biol Med. 1986;181(1):144-50.

4. Posluszny JA Jr, Muthumalaiappan K, Kini AR, Szilagyi A, He LK, Li Y, et al. Burn injury dampens erythroid cell production through reprioritizing bone marrow hematopoietic response. J Trauma. 2011;71(5):1288-96. doi: $\quad 10.1097 /$ TA.0b013e31822e2803.

5. Curinga G, Jain A, Feldman M, Prosciak M, Phillips B, Milner S. Red blood cell transfusion following burn. Burns. 2011;37(5):742-52. doi: 10.1016/j.burns.2011.01.016.

6. Kilyewala C, Alenyo R, Ssentongo R. Determinants and time to blood transfusion among thermal burn patients admitted to Mulago Hospital. BMC Res Notes. 2017;10(1):258. doi: 10.1186/s13104-017-2580-2.

7. Siah S, Elmaataoui A, Messaoudi N, Ihrai I, Kamili ND. [The mechanism of non-immune haemolytic anaemia in burns patient]. Ann Biol Clin (Paris). 2010;68(5):603-7. doi: 10.1684/abc.2010.0473.

8. Kohanpour MA, Peeri M, Azarbayjani MA. The effects of Glycyrrhiza glabra L. extract use with aerobic training on inflammatory factors and cognitive state in elderly with mild cognitive impairment. J HerbMed Pharmacol. 2017;6(4):178-84.

9. Cheraghi M, Asadi-Samani M. Hemapoietic medicinal plants based on ethnobotanical documents of Iran: a strategy to develop nature-based drugs effective on anemia. Der Pharmacia Lettre. 2016;8(5):393-9.

10. Massone F. Anestesiologia Veterinária: Farmacologia e Técnicas. 2nd ed. Rio de Janeiro, Brazil: Guanabara Koogan; 1994.

11. Hillyer EV, Quesenberry KE. Ferrets, rabbits and rodents: clinical medicine and surgery. New York: USA: WB Sounders; 1997.

12. Tavares Pereira Ddos S, Lima-Ribeiro MH, de PontesFilho NT, Carneiro-Leao AM, Correia MT. Development of animal model for studying deep second-degree thermal burns. J Biomed Biotechnol. 2012;2012:460841. doi: 10.1155/2012/460841.

13. Jones KW. Clinical hematology and fundamentals of hemostasis. 5th ed. Philadelphia, USA: FA. Davis Co; 2009.

14. Bain BJ. Goldman's Cecil Medicine. 24th ed. Philadelphia, USA: Elsevier Saunders; 2011.

15. Vajpayee N, Graham SS, Bern S. Henry's Clinical Diagnosis and Management by Laboratory Methods. 22nd ed. Philadelphia, USA: Elsevier Saunders; 2011.

16. Cantwell M. A review of important facts, about Potato glycoalkaloids. Perishables Handling Newsletter. 1996;87:26-7. 